\title{
DESIGN, DEVELOPMENT, AND CONSTRUCTION OF SNS EXTRACTION FAST KICKER SYSTEM *
}

\author{
W. Zhang, J. Sandberg, R. Lambiase, Y.Y. Lee, R. Lockey, J. Mi, T. Nehring, C. Pai, N. Tsoupas, \\ J. Tuozzolo, D. Warburton, and J. Wei \\ Brookhaven National Laboratory, Upton, NY 11973, USA
}

K. Rust, and R. Cutler

Oak Ridge National Laboratory, Oak Ridge, TN 37831

\begin{abstract}
The SNS accumulator ring extraction fast-kicker system was design, developed, and prototype tested at the Brookhaven National Laboratory. Its construction has just begun. The system is for one-turn fast extraction ejecting proton beam from the ring into the extraction septum gap and further deflecting into the ring-to-target beam transport line. The system consists of fourteen highvoltage modulators, their local control and auxiliary systems, and fourteen window frame magnet sections. High-voltage transmission cables will be used for pulse transmission from modulators to their corresponding magnet sections. The high-voltage and high-current pulse has a rise time about $200 \mathrm{~ns}$, a pulse duration about 700 ns, and a current amplitude above 2500 Amp per modulator. The modulator design features a Blumlein Pulse-Forming-Network with ultra-low inductance high energy storage pulsed capacitors, an ultra-fast high-power hollow anode thyratron, a parallel resistor stack for low beam-impedance termination, and a saturable inductor stack for beam current isolation and pulse rise time sharpening. This design is driven by the considerations of low beam loss, high maintainability and reliability. All high voltage modulators will be placed outside the ring tunnel and the system is immune to one-kicker failure. In addition, the enlarged magnet aperture can accept all four working points. The design concept has been successfully proven by the prototype test. The techniques, considerations, and other related issues of the system design, development and construction are discussed in this paper.
\end{abstract}

\section{INTRODUCTION}

The SNS beam extraction will be a single turn, two-step process. The fast extraction kicker will eject beam into a Lambertson septum and deflecting further into the Ring to Target Beam Transport (RTBT) line.

A set of fourteen full aperture kickers will be used to eject $1 \mathrm{GeV}$ proton beam vertically from the Accumulator Ring. It will take place at one of the four dispersion free

\footnotetext{
* SNS is managed by UT-Battelle, LLC, under contract DE-AC0500OR22725 for the U.S. Department of Energy. SNS is a partnership of six national laboratories: Argonne, Brookhaven, Jefferson, Lawrence Berkeley, Los Alamos, and Oak Ridge.
}

straight sections, as shown in Figure 1. Seven kicker magnets are to be located upstream of the narrow quadrupole doublet and seven downstream of it.

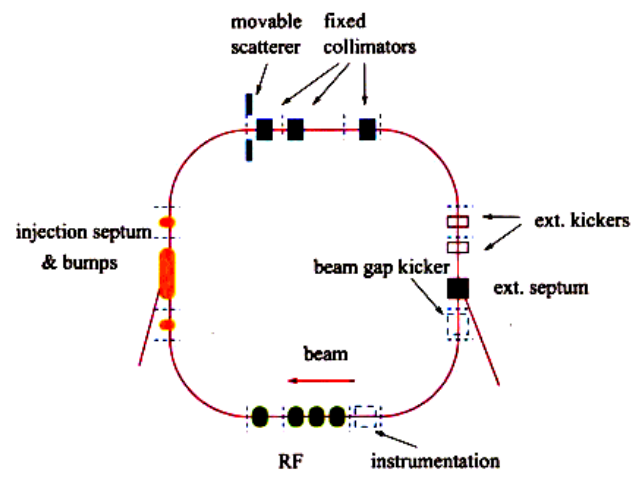

Figure 1: SNS Accumulator Ring Layout

A crucial part in this design is the high power pulse modulator system [1] [2] [3]. It is one of the largest fast kicker systems in its class. The combined maximum system output power will reach to several GVA. It will consist of fourteen high voltage modulators located outside of the tunnel in a dedicated service building, and their auxiliary power and control system. Pulse transmission will be carried out by high voltage pulsed cables from modulators to kicker magnets. The basic system layout is shown in Figure 2.

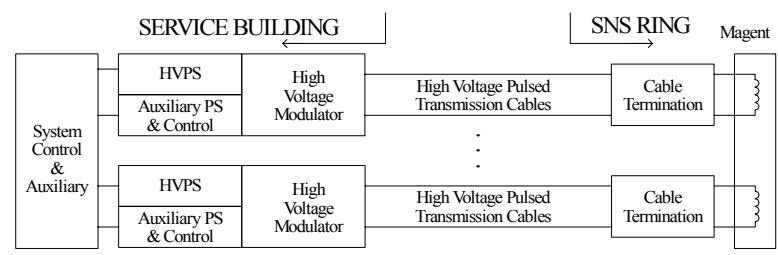

Figure 2: SNS extraction fast kicker system layout

The updated main parameter specifications [4] are listed in Table 1.

Table 1 Revised Main Parameter Specifications

\begin{tabular}{|l|l|}
\hline Beam Rigidity & $5.6575 \mathrm{~T}-\mathrm{M}$ \\
\hline Extraction Energy & $1.0 \mathrm{GeV}$ \\
\hline Extraction type & Single-turn \\
\hline Magnet window & Full aperture \\
\hline Beam revolution period & $945.4 \mathrm{~ns}($ at $1.0 \mathrm{GeV})$ \\
\hline
\end{tabular}




\begin{tabular}{|l|l|}
\hline & $911.1 \mathrm{~ns}$ (at $1.3 \mathrm{GeV})$ \\
\hline Beam gap during extraction & $250 \mathrm{~ns}$ \\
\hline Bunch length (full) & $645 \mathrm{~ns}$ \\
\hline Maximum extraction rate & $60 \mathrm{~Hz}$ \\
\hline Pulse flat-top length & $>700 \mathrm{~ns}$ \\
\hline Pulse Flat-top tolerance & $+/-3 \%$ \\
\hline Pulse rise time & $200 \mathrm{nS}(1 \%-95 \%)$ \\
\hline Pulse fall time & $<16.6 \mathrm{~ms}$ \\
\hline Kicker strength & $\begin{array}{l}1.276 \text { to } 1.775 \mathrm{mrad} \\
\text { per section }\end{array}$ \\
\hline Total deflection strength & $20.344 \mathrm{mrad}$ \\
\hline Kicker horizontal aperture & $120 \mathrm{~mm}$ to $211.3 \mathrm{~mm}$ \\
\hline Kicker vertical aperture & $166 \mathrm{~mm}$ to $243 \mathrm{~mm}$ \\
\hline Kicker length & $\begin{array}{l}390 \mathrm{~mm} \text { to } 505 \mathrm{~mm} \text { per } \\
\text { section }\end{array}$ \\
\hline Kicker magnet inductance & $\begin{array}{l}695 \mathrm{nH} \text { to } 789 \mathrm{nH} \text { per } \\
\text { section }\end{array}$ \\
\hline Operating voltage & $<35 \mathrm{kV}$ per section \\
\hline Operating current & $<2.5 \mathrm{kA}$ per section \\
\hline
\end{tabular}

This updated specification reflects the enlarged magnet apertures and increased output power to serve all working points of $\left(v_{x}, v_{y}\right)$ at $(6.23,6.2),(6.4,6.3),(6.23,5.24)$, and $(6.3,5.8)$. These four working points are the nominal tune near coupling resonance $v_{x}=v_{y}$, an alternative working point away from the structure lines, a split-tune working point for decoupling, and an old working point, respectively [5].

Sufficient space is reserved to add two more magnets and modulators for future $1.3 \mathrm{GeV}$ upgrade.

\section{DESIGN AND DEVELOPMENT}

To achieve maximum operability, maintainability, and lower beam impedance to minimize beam loss, as requested by SNS project, a new conceptual design was proposed in year 2000. This design features a Blumlein voltage doubler, a $25-\mathrm{ohm}$ parallel resistor for beam impedance termination, two 50-ohm impedance cable in parallel for pulse transmission, and full reflection at magnet doubling the current magnitude. The saturable inductor will provide impedance isolation for beam current, and become saturated during output current rising edge for dark current suppression. All high maintenance devices will be located in service building; no active or dissipative components will be used in the radiation area. In Figure 3, the main schematic is illustrated.

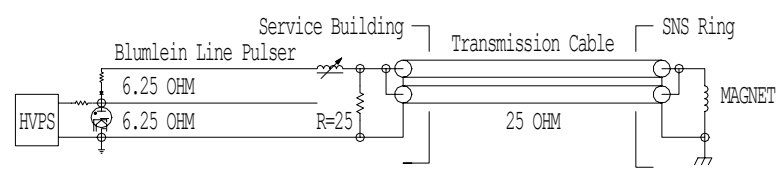

Figure 3: Simplified main schematic of SNS extraction kicker

Among many advantages offered by this design, the margin of the design parameter to operation is largely increased. Our physicists immediately recognized this feature and they seized the opportunity to improve physics performance of the main accumulator ring. The kicker magnet apertures have been enlarged to accommodate all four working points, further reduced beam impedance, and increased beam acceptance at kicker magnets. Compare with the year 2001 parameters, the required total output power of the kicker modulators have to be increased by $86 \%$, and the margin of designed voltage over operating voltage shrink to $42 \%$ per modulator from $88 \%$ - $173 \%$ per modulator.

Although the maximum charging voltage is $50 \mathrm{kV}$, we set the operation voltage limit of the modulator at below $35 \mathrm{kV}$ for the concerns of device lifetime, system reliability, fault tolerance, and system sustainability.

The Blumlein pulser can be implemented by two sets of high voltage cable pulse-forming lines or double deck of lumped L-C pulse forming networks. The later option was chosen for the compactness.

As constrained by the budget and very tied project schedule, the research and development efforts shall be limited only to the necessities to meet the minimum performance requirements. However, the criticality of the fast extraction kicker performance demands full and detailed verification on each stage of the system design and development. Therefore, we conducted design analysis, parameter optimization, and computer simulations to verify the design principle. Then, a proofof-principle model circuit was build and tested. Its output current waveform nicely matched computer simulation. Further, a full-scale prototype modulator has been designed, constructed, and tested at Brookhaven National Laboratory. Its test results successfully demonstrate the design concept.

Mechanical design of the high voltage pulse modulator provides many features for easy maintenance, such as, the modulator internal structure can be lifted out from its fluid container for device change and pulse shaping. Figure 4 shows the prototype modulator.

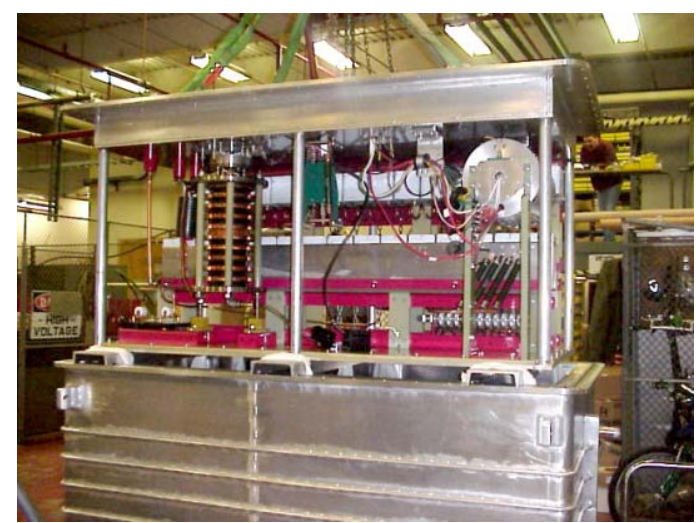

Figure 4: SNS extraction fast kicker modulator prototype

Varies tests have been conducted on the prototype modulator.

$>$ For pulse shape verification and construction check, the unit was tested up to $40 \mathrm{kV}$ in air, in single shot mode. 
$>$ At $35 \mathrm{kV}$ full rated operation voltage, the prototype unit has been tested in silicon fluid at $60 \mathrm{~Hz}$ repetition rate for over 200 hours at August 2002.

$>$ A $40 \mathrm{KV}, 60 \mathrm{~Hz}$ repetition rate, 12 hours continuous accelerated lifetime test has been completed at August 2002.

$>$ A $45 \mathrm{kV}, 30 \mathrm{~Hz}$ repetition rate, 8 hours continuous accelerated lifetime test has been completed at August 2002.

$>$ A $50 \mathrm{kV}$ single shot mode test on going.

Figure 5 and Figure 6 show the magnet current waveforms at $50 \mathrm{kV}$.

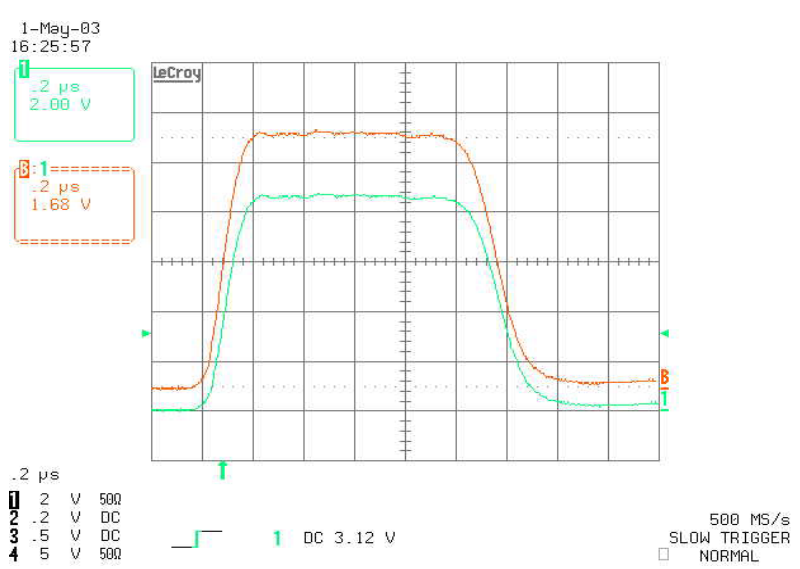

Figure 5: Magnet current waveform at $50 \mathrm{kV}$

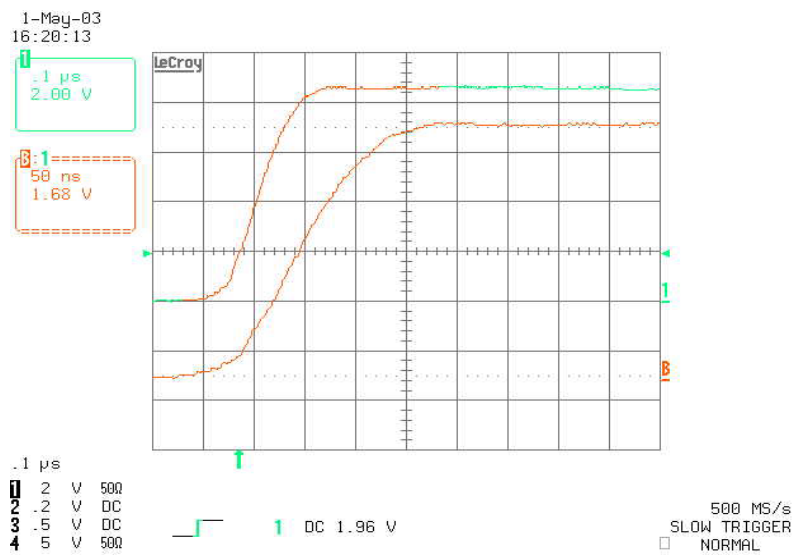

Figure 6: Magnet current rise time at $50 \mathrm{kV}$

In this design, all critical components are commercially available, which makes the design very cost effective. The main switch is an E2V CX1925X hollow anode thyratron rated for $80 \mathrm{kV}$ and $15 \mathrm{kA}$. Its high voltage hold-off rating, high conduction speed, and reverse conduction capability make it a top choice for this application. The DOW Corning 561 silicon fluid is used for insulation. General Atomic Energy Product is the supplier of the ultra low inductance, $15 \mathrm{nH}$, silicon fluid filled high-energy pulse capacitors for PFN. Twelve Eupec's $6 \mathrm{kV}$ fast recovery diodes are used in reversing diode stack. Triaxial high voltage pulse cables from Times Microwave will be used for pulse transmission. The $50 \mathrm{kV}$ ALE high voltage capacitor charging power supply will be used one for each modulator system.

High voltage components specifications, testing methods, and technical standards are critical to ensure the system reliability. For example, the coaxial high voltage cables used in the prototype test were hi-potted to $100 \mathrm{kV}$ during acceptance test; the high voltage pulse capacitors were also hi-potted to $100 \mathrm{kV}$ in factory test; and the thyratron is rated and tested at a level more than twice of the operation voltage. So far, the performance and reliability of the high voltage components has been satisfactory, and no critical device failures have been observed.

\section{CONSTRUCTION STATUS}

The design and development stage of the SNS extraction fast kicker project has been concluded last year. Applied Power systems, a commercial company, has been awarded the contract to construct all fourteen high voltage modulators and corresponding auxiliary systems as specified and designed by Brookhaven National Laboratory.

Traditionally, all our high voltage, high current, and high-speed fast kicker modulators were designed, developed, and constructed at Brookhaven. This is the first time, we use commercial vendor to construct production units of the high voltage pulse modulators. The final design review has been completed; two meetings for progress check have been conducted at vendor's facility. The production is in progress.

\section{ACKNOWLEDGEMENT}

We would like to express our appreciations to Mr. W.A. Morris of ISIS, Dr. R. Sheldrake of E2V, Mr. R. Cooper and Mr. R. Hartsock of General Atomics for their expert advice and technical support.

\section{REFERENCES}

[1] W. Zhang, et al., "High Power Fast Kicker system for SNS Beam Extraction", Conference Record of the Twenty-Fifth International Power Modulator Symposium and 2002 High Voltage Workshop, June 30-July 3, 2002, pp 262-265.

[2] W. Zhang, et al., "A New Conceptual Design of the SNS Full Turn Fast Extraction Kicker Power Supply System", Proceedings, 2001 Particle Accelerator Conference, June 2001, pp. 3714-3716.

[3] W. Zhang, et al., "SNS full Turn Fast Extraction Kicker System", BNL Internal Technical Proposal Presentation, July 2000.

[4] N. Tsoupas, et al., "Beam Extraction from the SNS Ring”, draft paper for SNS Design Manual, internal communication, Nov. 2002.

[5] J.Wei, et al., "Evolution of the Spallation Neutron Source Ring Lattice", 20TH ICFA Advanced Beam Dynamics Workshop, Chicago, IL, April 2002. 